\title{
Vestido de Pedra: abordagem semiótica de um vídeo
}

Daniele da Rocha Schneider, PPGIE/UFRGS, dani.qmc@gmail.com

Dinorá Fraga, UFRGS, dradmf@terra.com.br

Carla Borba, UFRGS, carlaborba.arte@gmail.com

Ângela Carine Oviedo, SENAI, angelacarine@gmail.com

Daniel dos Santos Telechi, SENAI, danieltelechi@yahoo.com.br

\section{Resumo}

O trabalho analisa o vídeo Vestido de Pedra, da artista gaúcha Carla Borba. Esse vídeo se constitui em uma ação performática baseada na confluência de imagem em movimento e som, gerando pela inter-relação dessas linguagens seus efeitos de sentido sobre a condição da mulher na sociedade moderna, segundo a teorização dos autores. A análise foi realizada no âmbito da teoria semiótica, considerando o percurso gerativo de sentido nos níveis fundamental, narrativo e discursivo. O estudo evidencia a semiótica como possibilidade de criação de significações sócio culturais e, nessas, de significações científicas. Indica-se sua característica interdisciplinar, por seu método fenomenológico e hermenêutico de leitura característico das ciências sociais aplicadas. A análise foi produzida, a partir de teorias e metodologia de análise textual, considerando a produção de sentido de usuários do vídeo, entre esses, alunos de uma escola de ensino profissionalizante.

Palavras Chave: tecnologia digital, vídeo, análise semiótica

\section{Dress stone: a semiotic approach of a video}

\begin{abstract}
The paper analyzes the video "Dress Stone" of the gaucho artist Carla Dias. This video constitutes a performative action based on the convergence of moving image and sound, generating the interrelationship effects of these languages and their meanings. The analysis was performed under the semiotic theory, considering the generative trajectory of meaning at the elementary, narrative and discursive levels (Greimas, 2006). The study shows semiotics as an enabler of creating sociocultural and scientific meanings. It indicates its interdisciplinary characteristic by its phenomenological and hermeneutic reading method being the characteristic of the Applied Social Sciences. The analysis was produced from theories and methodology of textual analysis, developed in the classroom Seminar of Linguistics and Semiotics Analysis of verbal and non-verbal texts, in the PGIE in the current semester.
\end{abstract}

Keywords: Digital Technology, Video, Semiotics Analysis 


\section{Vestido de Pedra: do que se trata}

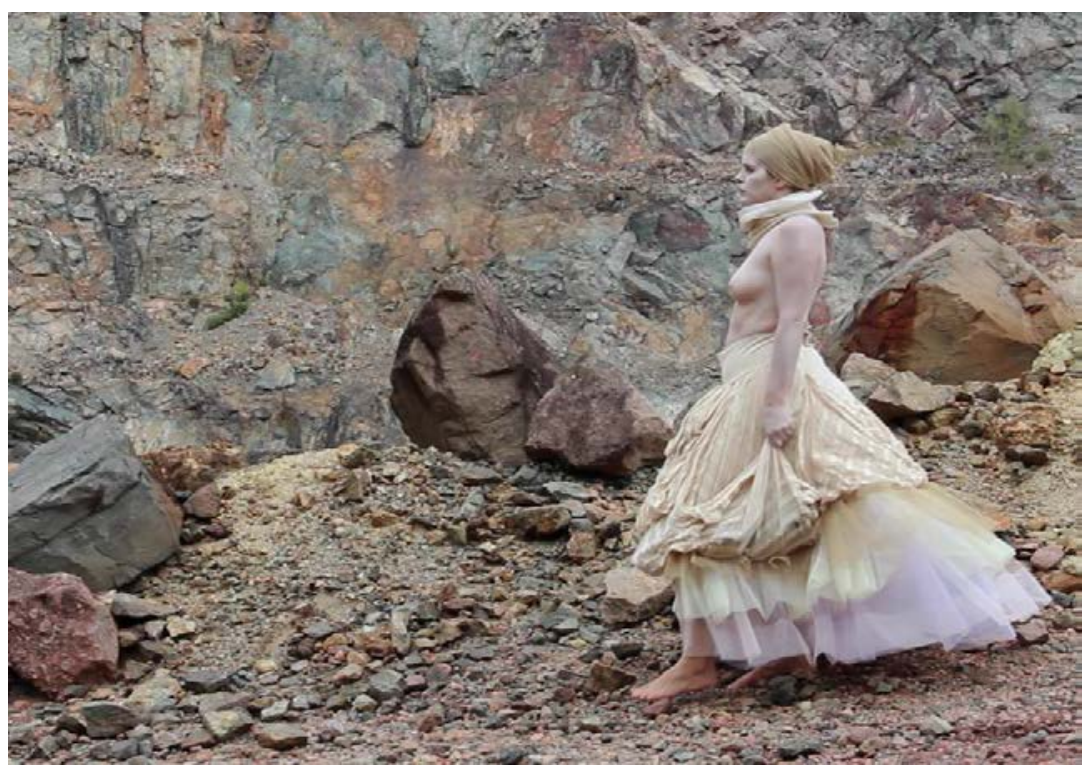

Figura 01 - Carla Borba, vídeo Vestido de Pedra - Mina do Camaquã, still de vídeo HD - 10 ‘00’’, 2012. Imagem: Rafael Pagatini, trilha sonora: Carina Levitan e edição: Camila Weinmann

O vídeo Vestido de Pedra (Figura 01) faz parte da produção artística de Carla Borba $^{1}$ e envolve a relação entre a performance-arte, perpassando de forma poética pelo sentido de conexão, a partir da ideia de corpo sedimento e do processo de construção de sentido na educação. A performance-arte, dentre diferentes conceituações devido seu caráter híbrido, consiste em uma experiência corporal e afetiva em um determinado espaço e tempo, convertendo-se em uma linguagem de ativação de uma plataforma de reflexão e discussão. A performance como recurso para o processo de aprendizagem apresenta-se como uma linguagem potente, pois além de possuir uma natureza híbrida envolvendo diferentes linguagens (vídeo, fotografia, web arte, música, teatro, artes visuais, dança, literatura) possibilita a criação de sentido do ser conectado, sujeito do seu discurso.

A artista desenvolve sua pesquisa a partir dos desdobramentos da performance nas linguagens fotográficas e videográficas como interfaces entre o visível e o invisível, entre a materialidade do corpo e da sua ação sobre as coisas do mundo. Para a artista o corpo do performer arquiva, através de seu deslocamento no espaço e no tempo, as experiências vividas, os fragmentos de lembranças, de cenas do cotidiano, de possibilidades poéticas. Experiências e percepções são em seu imaginário imagens as quais, inicialmente, transforma em performances. Dessa forma, a relação entre imagem e performance se constitui como o elemento ativador principal de sua prática artística.

A proposição corpo sedimento expande os aspectos inerentes à linguagem performática e a imagem, dessa forma, se constitui como memória de experiências vividas em diferentes lugares e temporalidades. O vídeo Vestido de Pedra envolve, portanto, as ideias de corpo, imagem, tempo e espaço em um processo de acumulação e arquivamento, no qual o corpo registra e produz imagem a partir da performance.

O corpo sedimento, em sua essência, é polimorfo, e são justamente os processos artísticos que fazem dele um corpo paradoxal, metamórfico. O corpo sedimento, para a artista, é o registro, é a deposição dos diferentes acontecimentos vividos, camadas de 
formação constituídas de diferentes elementos: o amor, o medo, a dor, a alegria, a saudade, a morte, os desejos, o poder, a fé, o sexo, as lembranças, enfim, tudo o que é passível de marcar nosso constucto, nossa carne. Mas, acima de tudo, o corpo sedimento se remodela a cada lugar que passa, em uma relação de simbiose com o espaço e com o tempo. Um corpo que já esteve em toda parte, pois seu estado de sedimento implica a eterna transferência de um lugar para o outro, tornando-o um corpo ambíguo, ao mesmo tempo um corpo registro, repleto de marcas e imagens em constante devir.

No trabalho Vestido de Pedra, a imagem que surgiu inicialmente foi a de uma mulher de vestido longo e pesado entrando no mar. Uma cena bastante comum no imaginário feminino, uma mulher que se suicida entrando no mar ou no rio com os bolsos cheios de pedras. Em Hamlet de Shakespeare, a personagem Ofélia morre no rio afogada pelo peso que comportava e, ainda na biografia da escritora Virgínia Woolf, a qual coloca pedras em seu casaco para a sua entrada derradeira no rio.

A imagem do vestido se constitui de forma gradativa nas anotações e pesquisas da artista. Como referência importante foram utilizadas duas ideias de vestido, a partir dos retratos da rainha ElizabethI (Figura 02) e dos vestidos de orixás da cultura afrobrasileira (Figura 03). O formato dos vestidos da rainha, seduziram a artista, pois promoviam a sensação de opulência e força, já que eram formas bastante volumosas e davam uma impressão paradoxal de desconforto. Quanto aos Orixás, a cor dourada do vestido de Oxum² e o volume da saia também influenciaram na concepção do vestido.

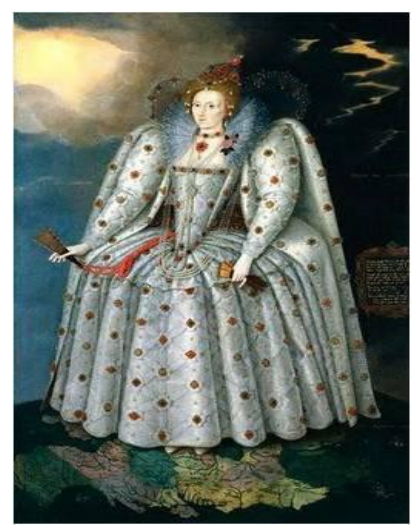

Figura 02 - Rainha Elizabeth I, O Retrato Ditchley. Marcus Gheeraerts, o jovem, Óleo sobre tela, 1592.

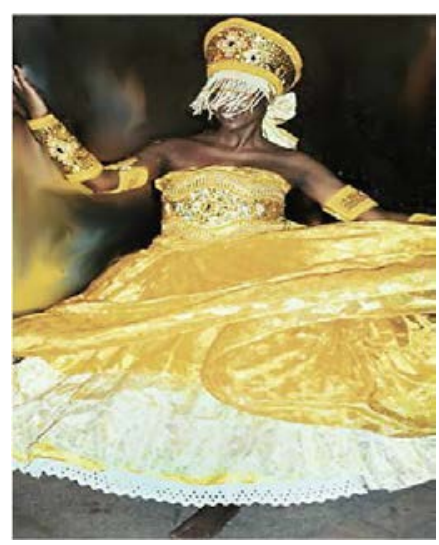

Figura 03 - Ritual de Candomblé em homenagem ao Orixá Oxum. Imagem de referência, Vestido de Pedra. 
Outro elemento que fazia parte da imagem que tinha em mente, em relação à performance Vestido de Pedra correspondia ao lugar onde o vestido seria utilizado. O lugar da ação, o ambiente que envolveria essa mulher. Uma pedreira seria o lugar ideal, pois as rochas estariam ali em abundância para ela carregar. Além de a pedreira ser um lugar de exploração mineral a céu aberto e de representar um impacto ao meio ambiente ela também carrega em sua formação o registro do trabalho árduo de homens e máquinas. A pedreira é como a abertura forçada do arquivo geológico. Um lugar apropriado para o processo árduo de acumulação de temporalidades para o corpo sedimento.

Dessa forma, a artista passou a procurar pedreiras. Foi então que conheceu as Minas do Camaquã, na região sudoeste do Rio Grande do Sul, distante $60 \mathrm{Km}$ de Caçapava do Sul e $300 \mathrm{Km}$ de Porto Alegre ${ }^{3}$. Em 1865 a exploração de jazidas de cobre reconfigurou a paisagem, e a região recebeu uma grande leva de trabalhadores promovendo o seu desenvolvimento. No entanto, devido ao esgotamento das reservas de cobre, as atividades encerraram em 1996, e hoje a mina está abandonada, assim como boa parte da região. Na primeira viagem a Caçapava, ela encontrou um lugar de paisagem belíssima com formações rochosas peculiares representativas de um período em que a região foi banhada pelas águas do mar, seguido de um período de clima desértico. A performer conheceu mais um lugar que ativou sua condição de corpo sedimento e as possibilidades de conexão com tempos infinitos.

O vídeo Vestido de Pedra, produzido em uma pedreira - com duração de dez minutos - uniu a força da imagem, enquanto presença estética de um corpo modelado por um vestido e por um ambiente repleto de cores, texturas e formas. Também acentuou a força da ação de incluir pedras nos bolsos do vestido, demonstrando a contraposição entre a imponência do lugar e o gesto intimista de guardar para si fragmentos daquele espaço grandioso. Contudo, a postura que a artista mantem no desenrolar da performance salienta a presença de uma mulher que busca manter uma imagem harmoniosa, mesmo em situações incomuns que lidam com uma certa violência.

Durante a realização do vídeo o corpo assume as especificidades da performance e se apropria da representação no espaço e no tempo. A performance se constitui como plano bidimensional e o corpo da artista internaliza questões inerentes à linguagem videográfica. Nestes casos, os gestos presentes na performance são imagens e o vídeo transforma a experiência em um plataforma de troca e expressão. O vídeo Vestido de Pedra representa uma ínfima parte do corpo sedimento, da artista cartografado. Os arquivos foram abertos, a conexão com as coisas do mundo foi ativada.

Nesse contexto a performance e o vídeo geram uma leitura da vida a partir da subjetividade e vivências de cada um, criando novas possibilidades de postura frente a ideia de conexão e interação com o mundo, aspectos inerentes ao campo da educação.

\section{Refletindo com a semiótica sobre o Vestido de Pedra}

A reflexão sobre o vídeo Vestido de Pedra se fundamenta na análise semiótica, procurando identificar os efeitos de sentido produzidos. A leitura semiótica foi realizada por professores e alunos de uma escola técnica. A semiótica, ao examinar os procedimentos da organização textual e os mecanismos enunciativos, procura descrever e explicar "o que o texto diz e como faz para dizer o que diz” (Barros, 2005, p.11).

Os mecanismos e as relações do percurso gerativo de sentido produzidos perpassam os níveis fundamental, narrativo e discursivo. Esse modelo tripartido é "uma sucessão de patamares que mostra como se produz e se interpreta o sentido (de um 
texto), num processo que vai do mais simples e abstrato ao mais complexo e concreto". (Fiorin, 2000, p.17). Esses patamares possuem uma organização própria e complementar, denominada de sintaxe e semântica, na qual a primeira se torna responsável pela materialidade da segunda.

No primeiro patamar, das estruturas fundamentais, surge "a significação como uma oposição semântica mínima” (Barros, 2005, p. 13), a qual se caracteriza como base de sustentação das demais etapas do percurso gerativo. O segundo patamar, o narrativo, organiza a narrativa do ponto de vista de um sujeito. Apresenta um ordenamento de formas discursivas pelo qual o enunciatário vai tomando conhecimento ao ler o texto (Greimas,1996).

O último patamar, das estruturas discursivas, se constitui no mais concreto e complexo, pois se aproxima mais da manifestação textual, entendida como manifestação textual, assumida pelo sujeito da enunciação. Estudam-se as relações entre os elementos da enunciação e suas relações com o enunciado, viabilizando assim a compreensão da significação do discurso, essenciais na análise de um texto, no caso específico, do vídeo Vestido de Pedra.

A enunciação é o ato de produção do discurso (Fiorin, 2000) a qual representa uma resposta a algo e é construída como resposta, implicando sempre a presença de um enunciador (quem enuncia) e de um enunciatário (quem recebe a enunciação). Segundo Barros (2005), há uma relação entre enunciação/enunciado e entre enunciador/enunciatários. Entre os primeiros é necessário a existência de um discurso e entre os segundos, a necessidade de se realizar os atos da linguagem.

No vídeo, o cenário de fundo, um paredão de pedras robusto com cores e texturas distintas, contrasta com a cor clara e a leveza inicial do vestido. Esse enunciado nos remete a ideia de oposição semântica. Observamos, então, a presença da categoria semântica fundamental que tem sua origem na diferença, numa oposição. Na análise semiótica, essa categoria está na base da construção de um texto. Conforme Barros (2005, p. 14), "no nível das estruturas fundamentais é preciso determinar a oposição ou as oposições semânticas a partir das quais se constrói o sentido do texto".

A categoria de nível fundamental que identificamos no vídeo é peso/ versus /leveza. Esses termos possuem um traço semântico em comum, determinados pela relação de oposição, sendo sempre um eufórico (valor positivo) e outro disfórico (valor negativo). No vídeo, leveza, elegância, feminilidade expressos pelo vestido na fase inicial da narrativa são termos eufóricos e peso, desequilíbrio e força, expressos pela pedra ou pedras, são disfóricos (ausência de leveza).

A euforia e a disforia são categorias que se constroem no e pelo texto e são determinadas pelas relações sensoriais individuais em relação a performance desenvolvida. Nesse sentido, o peso não é necessariamente, em si, uma categoria disfórica, nem a leveza, será sempre, uma categoria eufórica. Essa relação é intrínseca a percepção de cada indivíduo em uma determinada situação de comunicação.

A partir da contraposição peso/leveza, podemos extrair também a oposição equilíbrio/desequilíbrio, resistência/ação sobre o meio e feminilidade/trabalho braçal, representado pela ação de incluir pedras nos bolsos do vestido (figura 04). 


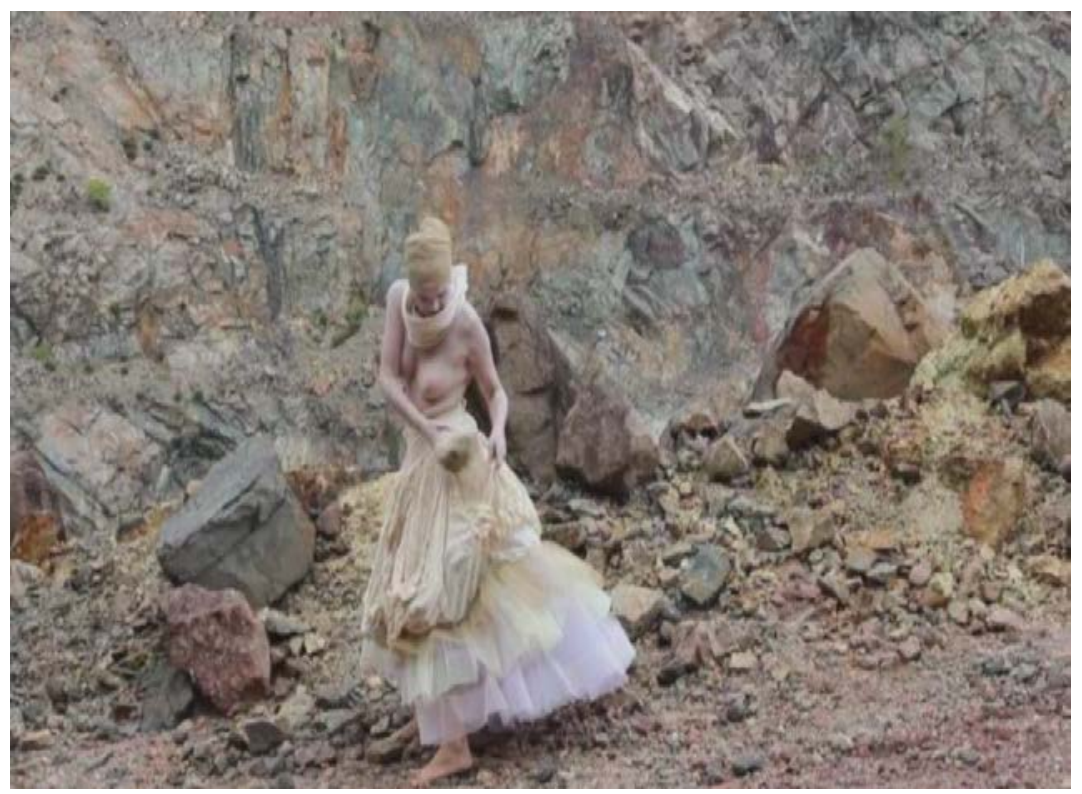

Figura 04 - Efeito de inclusão de pedras no vestido

Carla Borba, vídeo Vestido de Pedra - Mina do Camaquã, still de vídeo HD - 10 ‘00’, 2012.

Imagem: Rafael Pagatini, trilha sonora: Carina Levitan e edição: Camila Weinmann

O efeito de sentido produzido pelas formas de expressão foi um olhar fixo/versus/horizonte infinito, no qual observa seu entorno com uma postura leve (ausência do pisar, movimentos lentos, cor clara do vestido) e, aos poucos, começa a inserir pedras nos bolsos do seu vestido. Entre uma inserção e outra, para (ausência do movimento) e observa o ambiente. A repetição do movimento de inserção de pedras (enunciação não-verbal) altera seu estado inicial, a partir das sucessivas ações. Essa transformação de um estado noutro estado se constitui numa narrativa (figura 05).

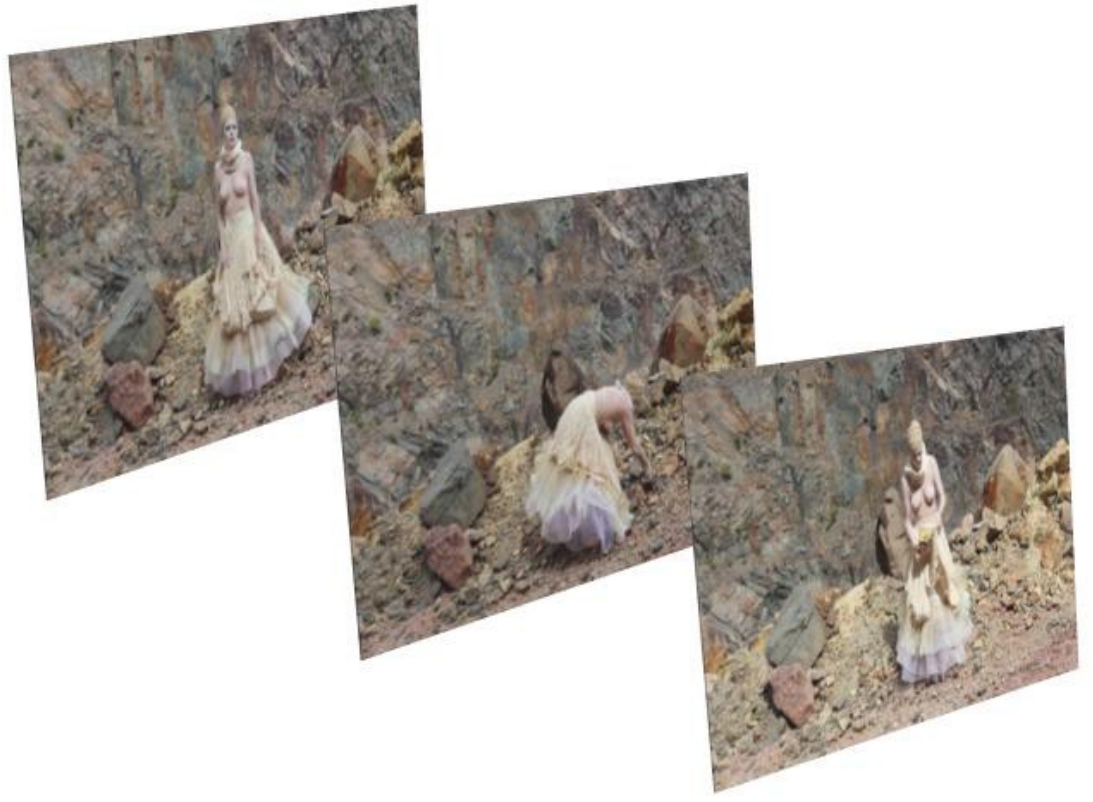

Figura 05 - Efeito de sentido produzido pela narrativa

Carla Borba, vídeo Vestido de Pedra - Mina do Camaquã, still de vídeo HD - 10 ‘00’, 2012.

Imagem: Rafael Pagatini, trilha sonora: Carina Levitan e edição: Camila Weinmann 
À medida que o número de pedras inseridas nos bolsos do vestido aumenta, aumenta o grau de dificuldade em relação ao deslocamento e equilíbrio. A relação do corpo com os objetos difere da inicial, pois as pedras que foram sendo inseridas transformaram o corpo do Ser feminino e agem sobre o mesmo. Isso perpassou pelos constituidores da narrativa (tropeçar, tentar equilibrar o corpo ao se movimentar e levantar).

Observa-se assim, um percurso de relações orientadas que inicia com um corpo leve, elegante e equilibrado, o qual passa a agir sobre o meio incorporando objetos que envolvem a ação. Essa ação sobre o espaço (ato de adicionar as pedras) aumenta o peso do vestido, provocando certo desequilíbrio nos gestos que executa. Segundo Borba (2012), representa a materialidade do corpo feminino, no qual a mulher revela seu avesso.

Os gestos de agregar pedras que a "figura feminina" executa pode representar a evolução e transformação do ser mulher. A partir disso é possível identificar que seu estado de leveza já não é o mesmo de antes, mas mesmo assim ela tenta negar este peso mantendo os mesmo gestos de leveza inicial, visivelmente negando o peso em seu vestido.

As pedras com as quais a "figura feminina" entra em conjunção podem ser a expressão do tema dos problemas e sentimentos enfrentados na jornada do ser feminino na sociedade. A cada pedra que a "figura feminina" coloca em seu vestido, há uma mudança no contínuo sonoro. Nesse instante um som de destaque e um efeito no vídeo (é um texto de imagem e movimento e sonoro), dando um efeito de ênfase do ato de pegar a pedra através da conjunção dessas duas linguagens: imagética e sonora.

Para cada problema que o ser feminino encontra em seu caminho, há uma atenção e uma tensão gerada. No vídeo o problema é proposto como o tema expresso na figura da pedra que em sua materialidade ser pedra é possível remeter ao tema desafio. Nesse percurso da conjunção do ser feminino com o tema, desafios do feminino na atualidade há um percurso narrativo expresso na continuidade de seus atos.

A significação de desafio é possível pelas figuras pedras pequenas e pedras grandes e pela ação de inicialmente a figura feminina entrar em conjunção pelo ato de pegar com as pedras pequenas para na continuidade de seus atos pegar as pedras grandes com as quais permanece. O desafio se apresenta com a mulher se tornando competente para o enfrentamento dos problemas maiores a partir de ser competente para agregar os problemas menores.

O texto vídeo, através do sujeito da enunciação, produz nos seus leitores um dado estado de verdade. Como exemplo, destacamos o momento em que o Ser feminino se desequilibra ao andar, produzindo o efeito de peso do vestido (Figura 06). Corrobora com essa sensação, o cenário robusto de uma pedreira, a qual culturalmente representa práticas econômicas de extração. 


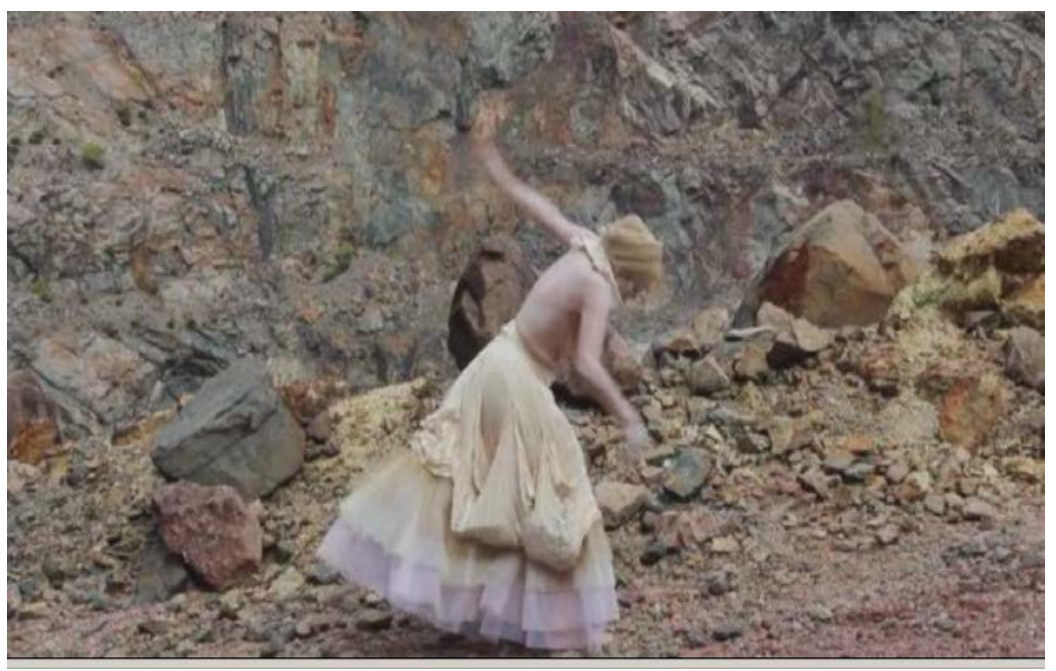

Figura 06 - Produção de efeito de peso no vestido

Carla Borba, vídeo Vestido de Pedra - Mina do Camaquã, still de vídeo HD - 10 ‘00’, 2012.

Imagem: Rafael Pagatini, trilha sonora: Carina Levitan e edição: Camila Weinmann

Ao escolher o cenário, o tempo e o espaço, o sujeito da enunciação, no caso o Ser feminino que atua em Vestido de Pedra, projeta o discurso. Para Barros (2005, p. 53), o discurso é a "narrativa "enriquecida" por todas essas opções do sujeito da enunciação, que marcam os diferentes modos pelos quais a enunciação se relaciona com o discurso que enuncia”.

Nesse sentido, Vestido de Pedra torna-se o objeto de comunicação entre o enunciador e seus destinatários, produzindo diferentes efeitos de sentido. Efeitos esses que podem ser perceptíveis de forma diferenciada por cada destinatário, pois a enunciação é pressuposta, ou seja, não se manifesta no texto.

A respeito do vestir pedra, ou o vestido de pedra, uma aluna, adulta e mãe, fala: "O peso da culpa é o que mais pesa”. "Culpa é um saco de tijolos, só carrega se quiser. Tem gente que carrega toda vida”. A culpa, no caso, está contida no campo semântico do peso da pedra.

O ato de colocar a pedra no vestido e o pé, na pedra, que, apesar do peso do vestido e do obstáculo das pedras no chão, não desequilibra a mulher. Daí a significação do desafio sendo vencido.

A "figura feminina" do vídeo Vestido de Pedra, se caracteriza, não somente pelas vestimentas que produzem efeitos de leveza, através do tecido, e suavidade através das cores, mas, também, por ter seus seios a mostra. Os seios são uma das principais características físicas do corpo feminino, caracterizam fragilidade.

Durante os movimentos, há transformações de sentidos, de espaço, de tempo. O tema nos remete ao ser feminino na sociedade, inserindo-se, cada vez mais, em todos os cenários, enfrentando e agregando problemas. Atualmente, é possível verificar a inserção cada vez maior do ser feminino em áreas que, por muito tempo, foram desempenhadas somente pelo sexo masculino. Um exemplo seria a área da Administração Pública. Segundo dados do IBGE em 2011, nessa área, a participação da mulher com 64,1\% já supera a do homem com 35,9\%.

Assim, a mulher agregou além das atividades que já possuía, como cuidar do lar e dos filhos, também atividades fora de casa, tornando-se, assim, um ser que não pode ser considerado frágil. A carga da mulher passou a ser muito maior, mas a mulher 
tem provado de que é capaz de acumular e desempenhar atividades em todas as esferas, sem perder a delicadeza e leveza do ser feminino.

\section{Na busca de uma conclusão}

A força interdisciplinar das linguagens digitais vem de seu poder de criar mundos e sentidos, constituindo-se como sistemas organizacionais de natureza ontogenética da aprendizagem, a partir da experiência estésica, motor dos processos cognitivos, porque impulsionam o sujeito para propor seu querer e seu poder (Greimas, 2006). Os sentidos que se constituem por essas linguagens articulam o eixo dos conceitos historicamente produzidos aos sentidos, em que a instância de produção é o corpo, como no caso dessa vídeo analisado.

Vemos em Fraga (2011), que as tecnologias midiáticas digitalizadas, com sua característica cibernética, geram realidades, por seus efeitos, chamados de veridicção. Devido as suas condições de linguagem numérica, criam novos efeitos visuais e auditivos, constituindo no ser humano que com elas convivem, novos modos de conhecer. Esses passam necessariamente pelo corpo, como sua instancia de produção, conforme relatos de Kerckhove, em "A Pele da Cultura" (1995), in Fraga (2011), referindo sobre experiências desenvolvidas no Laboratório de Análise dos Media da Simon Fraser University, em Vancouver.

Nestas experiências, a interação midiática é instituída no plano sensorial mais que no plano intelectivo. Retoma-se a importância de fenomenologia, como a lógica da expressão do sensível, cujo sentido ocorre antes no corpo que na consciência. Aí é o corpo que instaura a instancia do sentido comunicacional. Tal é a importância do vídeo que acabamos de analisar.

\footnotetext{
${ }^{1}$ Carla Borba é mestre em Poéticas Visuais pelo PPGAV do Instituto de Artes da UFRGS, como bolsista da CAPES. Participou de encontros de performance e exposições na França, Berlim e Brasil entre as quais destacam-se: Exposição Vão, Galeria TLZ, Porto Alegre, 2013 ; Performance Cabeça de Terra, Memorial do Rio Grande do Sul, Porto Alegre, 2012 ; Espetáculo Vão, Teatro Qorpo Santo e Sala Álvaro Moreyra, Porto Alegre, 2010/2011 ; Projeto DUETO, Casa M - $8^{\circ}$ Bienal de Artes Visuais do Mercosul, 2011; Convivência - Dez Anos de Bolsa Iberê Camargo, Fundação Iberê Camargo, Porto Alegre, 2010; Sua pesquisa envolve uma poética híbrida entre fotografia, performance, vídeo e teatro. Possui obras no acervo da Fundação Vera Chaves Barcellos e MAC-RS. Vive e trabalha em Porto Alegre.
}

${ }^{2}$ Oxum é um orixá feminino cultuado em todas as religiões afro-brasileiras. É o orixá das águas doces dos rios ecachoeiras, da riqueza, do amor, da prosperidade e da beleza. Em Oxum, os fiéis buscam auxílio para a solução de problemas no amor, uma vez que ela é a responsável pelas uniões, e também na vida financeira, a que se deve sua denominação de "Senhora do Ouro".

\footnotetext{
${ }^{3}$ Tive a informação da existência deste lugar através do funcionário da Companhia de Pesquisa de Recuros Minerais - CPRM, Norberto Lessa Dias. No município de Caçavapa do Sul a CPRM possui um depósito de mostras geológicas, como os 'testemunhos de sondagem' apresentados no capítulo II deste estudo. Existe um projeto na região da Bacia do rio Camaquã com o objetivo de encontrar novos depósitos de elementos minerais $(\mathrm{Cu}, \mathrm{Au}, \mathrm{Pb}, \mathrm{Zn}, \mathrm{Ag})$ para a geração de uma nova fase e desenvolvimentos social e econômico na região.
} 


\section{Referências Bibliográficas}

BARROS, D. P. Teoria Semiótica do Texto. São Paulo: Ática, 2005.

BORBA, C. Performance - Imagem: o corpo como processo de arquivamento, sedimentação e devir. Dissertação de Mestrado. Porto Alegre 2012.

FIORIN, J. L. Elementos de Análise do Discurso. 9. ed. São Paulo: Contexto, 2000.

FRAGA, D. AXT, M. Políticas do virtual. Editora Unisinos, 2011.

GREIMAS, A. J. Dicionário de Semiótica. Editora Cortez, SP, 1996.

IBGE, O estudo Mulher no Mercado de Trabalho: Perguntas e Respostas. Pesquisa Mensal de Emprego 2003-2011. Disponível em: http://www.ibge.gov.br/home/estatistica/indicadores/trabalhoerendimento/pme_nova/de faultestudos.shtm. Acesso em:11 mai. 2013. 